\title{
Real-Time Scattering-Contrast Imaging of a Supported Cobalt-Based Catalyst Body during Activation and Fischer-Tropsch Synthesis Revealing Spatial Dependence of Particle Size and Phase on Catalytic Properties
}

Pierre Senecal, ${ }^{\dagger, \dagger}$ Simon D. M. Jacques, ${ }^{\dagger, \S}$ Marco Di Michiel, " Simon A. J. Kimber,

Antonis Vamvakeros, ${ }^{\dagger, \ddagger}$ Yaroslav Odarchenko, ${ }^{\dagger, \ddagger}$ Ines Lezcano-Gonzalez, ${ }^{\dagger, \ddagger}$ James Paterson, ${ }^{\perp}$ Ewen Ferguson, ${ }^{\perp}$ and Andrew M. Beale ${ }^{* \dagger,+(i)}$

${ }^{\dagger}$ Research Complex at Harwell, Rutherford Appleton Laboratory, Didcot, Harwell OX11 OFA, U.K.

${ }^{\ddagger}$ Department of Chemistry, University College London, 20 Gordon Street, London WC1H 0AJ, U.K.

${ }^{\S}$ University of Manchester South, I13 OX11 ODE \& School of Materials, University of Manchester, Manchester, Lancashire M13 9PL, U.K.

"ESRF-The European Synchrotron, 71 Avenue des Martyrs, 38000 Grenoble, France

${ }^{\perp}$ BP Chemicals, Conversion Technology Centre, HRTC-DL10 Saltend, Hedon, Hull HU12 8DS, U.K.

Supporting Information

ABSTRACT: A combination of time-resolved synchrotron $\mu$ $\mathrm{X}$-ray diffraction computed tomography $(\mu$-XRD-CT) and $\mu$ pair distribution function computed tomography ( $\mu$-PDF-CT) has been applied for the study of an individual $\mathrm{Co} / \gamma-\mathrm{Al}_{2} \mathrm{O}_{3}$ catalyst pellet during reduction and the early stages of the Fischer-Tropsch synthesis (FTS) reaction, revealing insight into the solid-state changes occurring from within such crystalline materials. Both sets of data were of sufficient quality so as to be able to follow the spatial dependency of $\mathrm{Co}$ speciation evolution from $\mathrm{Co}_{3} \mathrm{O}_{4}$ to $\mathrm{CoO}$ to face-centered cubic (fcc) Co metal nanoparticles. These data revealed the samples to be highly heterogeneous and contain two types of Co species: small $(\leq 6.5 \mathrm{~nm})$ nanoparticles that interact strongly with the $\gamma-\mathrm{Al}_{2} \mathrm{O}_{3}$ support which are difficult to reduce (remaining as $\mathrm{CoO}$ ) and nanoparticles that agglomerate and have little interaction or else are weakly interacting with the support but readily reduce in $\mathrm{H}_{2}$. The Co phase evolution under FTS conditions shows a strong dependence on the Co nanoparticle location; the complementarity between the observations made using $\mu$-XRD-CT vs $\mu$-PDF-CT allowed us to conclude that at the sample periphery a significant amount of agglomerated, weakly interacting with the support, small fcc Co metal nanoparticles $(\leq 7.5 \mathrm{~nm})$ oxidize to $\mathrm{CoO} / \mathrm{Co}_{3} \mathrm{O}_{4}$ during FTS, most likely due to the presence of water vapor produced during the reaction. Catalytic tests demonstrated that this oxidation coincided with a decrease in $\mathrm{CH}_{4}$ selectivity and increased water-gas shift (WGS) activity. This oxidation of fcc Co nanoparticles (i.e., the removal of the contribution to the XRD signal) also explains the observation of sintering previously reported for such catalysts in the early stages of the FTS reaction.

KEYWORDS: cobalt, Fischer-Tropsch, alumina, pellet, XRD-CT, PDF-CT, particle size

\section{INTRODUCTION}

Fischer-Tropsch synthesis (FTS), which produces long-chain alkanes, alkenes, or alcohols using synthetic gas ("syngas"; a $\mathrm{CO} / \mathrm{H}_{2}$ gas mixture), has risen to prominence in the past decade, primarily as a result of increased methane availability and the effects of an increasing oil price. ${ }^{1}$ This method of synthesis represents one of the more viable routes to replace gasoline or diesel fuel produced in the refinery by providing ultraclean fuels (without sulfur or other types of aromatic/ metal poisons), although it has also garnered much recent literary attention, as the technology has proven flexible for the production of light hydrocarbons and oxygenates. $^{2-5}$ FTS proceeds via a hydrogenation reaction to form olefins and alkanes.

Olefin formation:

$n \mathrm{CO}+2 n \mathrm{H}_{2} \rightarrow \mathrm{C}_{n} \mathrm{H}_{2 n}+n \mathrm{H}_{2} \mathrm{O}$

Alkane formation:

Received: November 3, 2016

Revised: January 11, 2017

Published: January 31, 2017 


$$
n \mathrm{CO}+(2 n+1) \mathrm{H}_{2} \rightarrow \mathrm{C}_{n} \mathrm{H}_{2 n+2}+n \mathrm{H}_{2} \mathrm{O}
$$

For the synthesis of middle distillates and waxes, there is a clear advantage to be realized by the utilization of cobalt-based catalysts. They are a more economically viable choice than active FTS catalysts based on ruthenium. They also produce greater yields of linear $\mathrm{C}_{>5}$ and are generally operated at temperatures lower than those for classic iron-based systems, as there is less (no) need for appreciable water-gas shift (WGS) activity. ${ }^{1,3,6}$

Cobalt-based FTS catalysts are usually comprised of cobalt in its metallic form $\left(\mathrm{Co}^{0}\right)$, dispersed as small nanoparticles (typically $<10 \mathrm{~nm}$ diameter) on a microporous/mesoporous structure or an oxide support $\left(\mathrm{Al}_{2} \mathrm{O}_{3}, \mathrm{SiO}_{2}\right.$, and $\left.\mathrm{TiO}_{2}\right) \cdot \mathrm{Co}^{0}$ particles are believed to be the primary active sites, as they are present before, after, and during FTS and are thought to be necessary for a high product selectivity. ${ }^{7-11}$ However, other positively identified cobalt-containing species found in FTS catalysts include $\mathrm{Co}_{3} \mathrm{O}_{4}, \mathrm{CoO}, \mathrm{Co}_{2} \mathrm{C}$, and cobalt-support compounds (such as $\mathrm{CoAl}_{2} \mathrm{O}_{4}$ or $\mathrm{CoTiO}_{3}$ ). ${ }^{12}$ The state of Co under operational conditions, in order to determine the true nature of the active species and particularly the state of a deactivated catalyst, has been of much interest. Many reports have observed an "evolution" of the Co nanoparticle structure, including sintering, dispersion, and a decrease in scattering density thought to be due to interstitial $\mathrm{C}$ species, as well as an oxidation of (caused by water) to form cobalt oxides, all except in the most extreme of cases, lead to a loss in activity. ${ }^{9,12-17}$

The vast majority of previous in situ and operando studies utilize catalysts in powdered form, while industrial catalysts comprise high-surface-area supports which are subsequently extruded or pelletized into millimeter-sized "catalyst bodies" so as to minimize pressure drops along the length of the reactor vessel. ${ }^{18}$ In order therefore to obtain truly relevant information on the performance of an industrial catalyst, it needs to be studied not only under reaction conditions but also by using the correct physical form of the catalyst. Furthermore, this requires that catalysts not be simply studied as in the traditional single-point, OD manner but "chemically imaged" under reaction conditions in two and preferably three spatial dimensions in order to fully understand the importance of catalyst structure with function. ${ }^{19,20}$ Currently this imaging process results in each "pixel" of the acquired image containing a full spectrum or pattern, allowing for a more detailed appreciation of the complex behavior of real materials. Of late this spatially resolved chemical imaging process as a function of time has been referred to as 5D sample interrogation (three spatial dimensions, time, and the spectral dimension). ${ }^{21}$ To date only a handful of studies exist in which catalyst bodies have been imaged dynamically, mainly during catalyst preparation but more recently under catalytic reaction conditions. Some of these recent examples include the study by O'Brien et al., who used combined $\mu$-XRD-CT/ $\mu$-CT to monitor a $3 \mathrm{~mm} \mathrm{Ni} / \gamma$ $\mathrm{Al}_{2} \mathrm{O}_{3}$ catalyst body during methanation (hydrogenation of $\mathrm{CO})$ which focused on the nature and distribution of the active fcc Ni species on the catalyst, and more recently Price et al., who studied $\mu \mathrm{m}$-sized PtMo/C particles during the liquid phase hydrogenation of nitrobenzene. ${ }^{22,23}$ However, particularly relevant to this study has been the work by Cats et al. on $\mathrm{Co} / \mathrm{TiO}_{2}$ FTS catalysts, where a single particle of $\mathrm{Co} / \mathrm{TiO}_{2}$ in a $25 \times 25 \mu \mathrm{m}$ field of view has been imaged using $\mu$-XANES-CT with $30 \mathrm{~nm}$ resolution and under FTS conditions. ${ }^{11,24}$
In this work we report the results from an in situ X-ray diffraction computed tomography ( $\mu$-XRD-CT)/ $\mu$-PDF-CT pair distribution function computed tomography study of a 3 $\mathrm{mm} \mathrm{Co} / \gamma-\mathrm{Al}_{2} \mathrm{O}_{3}$ catalyst in order to understand the evolution of the $\mathrm{Co}$ environment during reduction and then under real FT conditions $\left(\mathrm{CO} / \mathrm{H}_{2}\right.$, ratio $\left.1: 2\right)$ in order to follow the evolution of the cobalt phases during these steps with the principal objectives being the determination of the nature of the active species under process conditions as well as insight into how to design a better-performing catalyst. ${ }^{25}$

\section{EXPERIMENTAL SECTION}

2.1. Scattering Contrast Imaging Methodology. The experiment was carried out at station ID15A of the European Synchrotron Radiation Facility (ESRF, Grenoble, France) using a monochromatic high-energy $E=93.028 \mathrm{keV}(0.1333 \AA), 50$ $\mu \mathrm{m}$ square pencil beam with diffracted X-rays recorded on a PerkinElmer flat panel detector. For each tomographic time slice, diffraction was recorded at 70 translations spaced $50 \mu \mathrm{m}$ across the body each with 60 rotations of $3^{\circ}$, corresponding to 4200 diffraction patterns (see Figure 1). Each diffraction

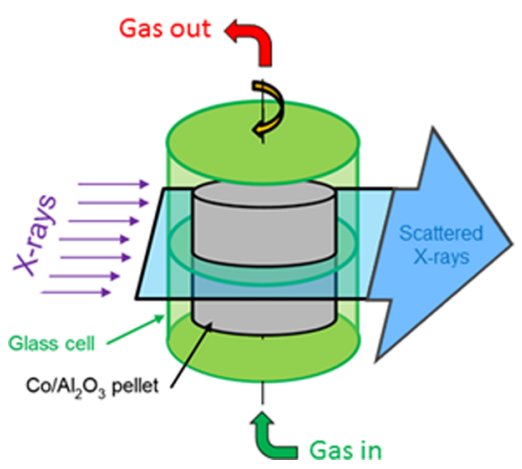

Figure 1. Schematic of glass reactor cell with a single vertically mounted $3 \times 3 \mathrm{~mm}$ pellet of $\mathrm{Co} / \gamma-\mathrm{Al}_{2} \mathrm{O}_{3}$. X-ray measurements were made in alternate $\mu$-XRD-CT/ $\mu$-PDF-CT "mode", profiling (70 translations and 60 rotations) a $2 \mathrm{D}$ cross section in the middle of the sample. Note that each arrow on the left corresponds to the incoming pencil beam.

pattern was recorded for $500 \mathrm{~ms}$. Powder ring data were obtained, and these were radially integrated (using datasqueeze software) after calibrating the detector and its response with a 8 nm $\mathrm{CeO}_{2}$ standard. ${ }^{26}$ For each observed intensity in these radially integrated patterns, a sinogram was constructed and then filtered back-projected to a $66 \times 66$ pixel image. Features were extracted from these reconstructed diffraction patterns that are presented herein. $\mu$-PDF-CT data collection was performed immediately after the collection of each $\mu$-XRD-CT data set by moving the detector much closer to the sample (ca. $20 \mathrm{~cm}$ ), such that very high values of momentum transfer, $Q=$ $30 \AA^{-1}$, were reached. On completion of $\mu$-PDF-CT acquisition, the detector was then moved back to a distance of $\sim 1 \mathrm{~m}$ for the next $\mu$-XRD-CT data set, and so this detector back and forth translation continued until the end of the experiment (see Figure $S 1$ in the Supporting Information). The program PDFGetX3 was used to extract pair distribution functions as described previously. ${ }^{25,27,28}$ In order to identify peaks in the experimental PDFs, we performed model calculations using PDFGui, and the relevant crystal structures. ${ }^{27,28}$ The processing and analysis of the considerable volume of diffraction/scattering data collected (over 50000 diffraction/scattering patterns) 
required the development of dedicated high-throughput software.

A $3 \mathrm{~mm}$ cylindrical pellet of a $10 \mathrm{wt} \% \mathrm{Co} / \mathrm{Al}_{2} \mathrm{O}_{3}$ catalyst was prepared by pore-volume impregnation of a $\gamma-\mathrm{Al}_{2} \mathrm{O}_{3}$ support using a solution of $\mathrm{Co}\left(\mathrm{NO}_{3}\right) \cdot 6 \mathrm{H}_{2} \mathrm{O}$ followed by roomtemperature drying and calcination at $300{ }^{\circ} \mathrm{C}$ (ramp $5{ }^{\circ} \mathrm{C}$ / min and dwell for $4 \mathrm{~h}$ ). Catalyst reduction was performed in a $4.0 \mathrm{~mm}$ outer diameter (o.d.) $/ 3.5 \mathrm{~mm}$ internal diameter (i.d.) glass reactor cell at atmospheric pressure under $39 \mathrm{~mL} / \mathrm{min}$ of $\mathrm{H}_{2}$ from room temperature to $450^{\circ} \mathrm{C}$ with a ramp of $2{ }^{\circ} \mathrm{C} / \mathrm{min}$ with dwell steps of $60 \mathrm{~min}$ at $150,310,350$, and $420{ }^{\circ} \mathrm{C}$. FTS was performed at $250{ }^{\circ} \mathrm{C}$ under $\mathrm{CO}(5 \%, 20 \mathrm{~mL} / \mathrm{min}), \mathrm{H}_{2}$ $(100 \%, 2 \mathrm{~mL} / \mathrm{min})$, and $\mathrm{He}(100 \%, 19 \mathrm{~mL} / \mathrm{min})$ giving a gas hourly space velocity (GHSV) of $\sim 23000 \mathrm{~h}^{-1}$. We note that, although FTS is traditionally performed at gas pressures of $\sim 20$ bar and with lower space velocities (leading to higher CO conversion), FTS activity data have previously been reported for such catalysts under conditions similar to those used here. $^{29-31}$

As has been reported previously, interrogation of the sample catalyst body took place after first mounting it within a $4 \mathrm{~mm}$ quartz reactor cell on an alumina rod (using ceramic cement), which was connected to a goniometer and rotation/translation stage via a custom-built Swagelok fitting which delivered gas from the bottom of the sample upward. Quartz wool was placed between the pellet and reactor cell wall in order to minimize reactant gas bypass. At the outlet to the reactor a loose fitting "hood" with gas extraction lines was placed over the outlet of the quartz cell, which prevents exposure to air via back flow. To maintain the correct temperature at the sample, two heat guns were mounted on the translation stage, which move with the reactor, thereby maintaining a constant sample temperature. The continuous flow of hot air around the cell from the two heat sources ensures a uniform temperature distribution, as has been previously shown. ${ }^{22}$

The data presented in this work are plotted in terms of reflection area or else using scaled intensities when quantifying the amount of cobalt present (as a ratio) of a particular crystalline phase. Intensity data were obtained from reflection profiling (via fitting of the Bragg peak using a Gaussian function) of the $\mathrm{Co}_{3} \mathrm{O}_{4}$ (311), $\mathrm{CoO}$ (200), and $\mathrm{Co}$ fcc (111) phases from their respective crystallographic data using GSASII. ${ }^{32}$ Subsequently from the ratio of these intensities the weight percent of $\mathrm{Co} \mathrm{fcc}$ is plotted by working from the basis that the total Co percentage is equal to $\mathrm{CoO}+\mathrm{Co}+\mathrm{Co}_{3} \mathrm{O}_{4}$. On the basis of the reproducibility of the data-fitting process we estimate the error on the quantities present to be $\pm 3 \%$.

2.2. Catalytic Testing. Complementary catalytic tests were performed in a $9 \mathrm{~mm}$ o.d. $/ 7 \mathrm{~mm}$ i.d. quartz tubular reactor, using two $3 \mathrm{~mm}$ cylindrical pellets of a $10 \mathrm{wt} \% \mathrm{Co} / \mathrm{Al}_{2} \mathrm{O}_{3}$ catalyst. Prior to the experiment, the catalyst was reduced under $\mathrm{H}_{2}\left(81.2 \mathrm{~mL} / \mathrm{min} ; 4 \% \mathrm{H}_{2}\right.$ in $\left.\mathrm{He}\right)$ at $450{ }^{\circ} \mathrm{C}\left(2^{\circ} \mathrm{C} \mathrm{min}^{-1}\right.$ to 450 ${ }^{\circ} \mathrm{C}$, held for $1 \mathrm{~h}$ ). Subsequently, the reaction temperature was fixed at $250{ }^{\circ} \mathrm{C}$ and FTS was performed at atmospheric pressure using a 1:2 gas mixture of $\mathrm{CO}(23.2 \mathrm{~mL} / \mathrm{min} ; 5 \% \mathrm{CO}$ in $\mathrm{He})$ and $\mathrm{H}_{2}\left(58 \mathrm{~mL} / \mathrm{min} ; 4 \% \mathrm{H}_{2}\right.$ in $\left.\mathrm{He}\right)$. The output gases were analyzed by mass spectrometry (Pfeiffer, Omnistar).

\section{RESULTS}

3.1. XRD-CT Data. The data shown in Figure 2 represent all of the summed $\mu$-XRD-CT data recorded from an entire $2 \mathrm{D}$ cross section of the $\mathrm{Co} / \gamma-\mathrm{Al}_{2} \mathrm{O}_{3}$ sample, acquired before and after reduction in $\mathrm{H}_{2}$ and after FTS activity studies. Only three

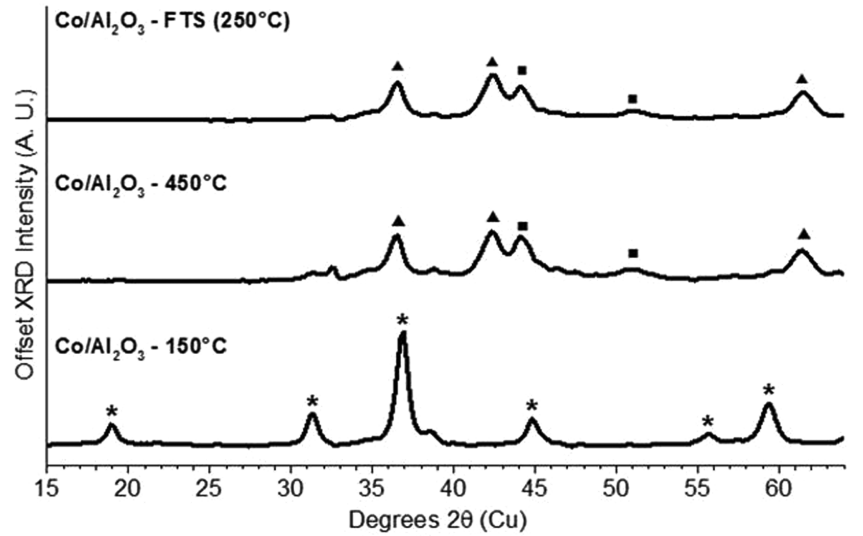

Figure 2. Summed $\mathrm{XRD}$ data over entire $2 \mathrm{D}$ data sets displayed as $1 \mathrm{D}$ patterns for $\mathrm{Co} / \gamma-\mathrm{Al}_{2} \mathrm{O}_{3}$ at beginning of the reduction (bottom), at the end of the reduction treatment at $450{ }^{\circ} \mathrm{C}$ (middle), and during FTS at $250{ }^{\circ} \mathrm{C}$ (top). For clarity, the signal pertaining to $\gamma-\mathrm{Al}_{2} \mathrm{O}_{3}$ has been subtracted and the angle corrected against $\mathrm{Cu} \mathrm{K} \mathrm{K}_{\alpha 1}$ radiation. Legend: $\mathrm{Co}_{3} \mathrm{O}_{4}(*), \mathrm{CoO}(\boldsymbol{\Delta})$, and $\mathrm{Co}$ fcc $(\boldsymbol{\square})$.

cobalt phases are observed throughout the duration of the experiments: the spinel phase $\mathrm{Co}_{3} \mathrm{O}_{4}, \mathrm{CoO}$, and metallic facecentered cubic (fcc) Co. ${ }^{7,10,33}$ At the beginning of the in situ experiment and as expected, $\mathrm{Co}_{3} \mathrm{O}_{4}$ obtained after calcination is the only cobalt-containing phase present in the XRD data. At the end of the reduction treatment $\left(@ 450{ }^{\circ} \mathrm{C}\right)$, the reduced sample is dominated by contributions ascribable to fcc Co and some unreduced $\mathrm{CoO}$, as is typically observed in $\mathrm{Co} / \gamma-\mathrm{Al}_{2} \mathrm{O}_{3}$ catalysts; this cursory analysis reveals that, in this instance, the $\mathrm{CoO}$ phase appears to be the majority phase present. ${ }^{7,34} \mathrm{~A}$ reduction in the intensity of the fcc Co (111) reflection $(\sim 30 \%)$ is observed at the end of the FTS process with the remainder of the diffraction pattern comparatively unchanged. In order to examine this more closely, shown in Figure 3 is a

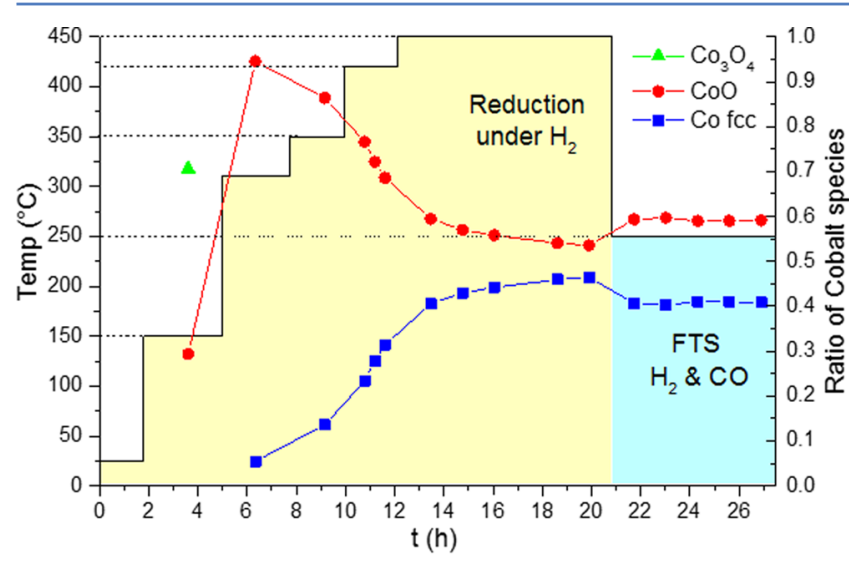

Figure 3. Composition profile compiled from the integrated and scaled reflection intensities for the various cobalt-containing phases $\left(\mathrm{Co}_{3} \mathrm{O}_{4} 220, \mathrm{CoO} 200\right.$, $\mathrm{Co}$ fcc (111)) from the summed 2D diffraction data observed throughout the $\mathrm{H}_{2}$ reduction process and during FTS on $\mathrm{Co} / \gamma-\mathrm{Al}_{2} \mathrm{O}_{3}$.

plot of the $2 \mathrm{D}$ summed composition as a function of time/ reaction conditions using the following (scaled) nonoverlapping reflections clearly ascribable to the respective crystalline phases (see Figure $\mathrm{S} 2$ in the Supporting Information): the (220) reflection at $31.30^{\circ} 2 \theta\left(\mathrm{Co}_{3} \mathrm{O}_{4}\right)$, the (200) reflection at $42.50^{\circ} 2 \theta(\mathrm{CoO})$, and the $(111)$ reflection at $44.50^{\circ} 2 \theta$ (fcc 
(a)
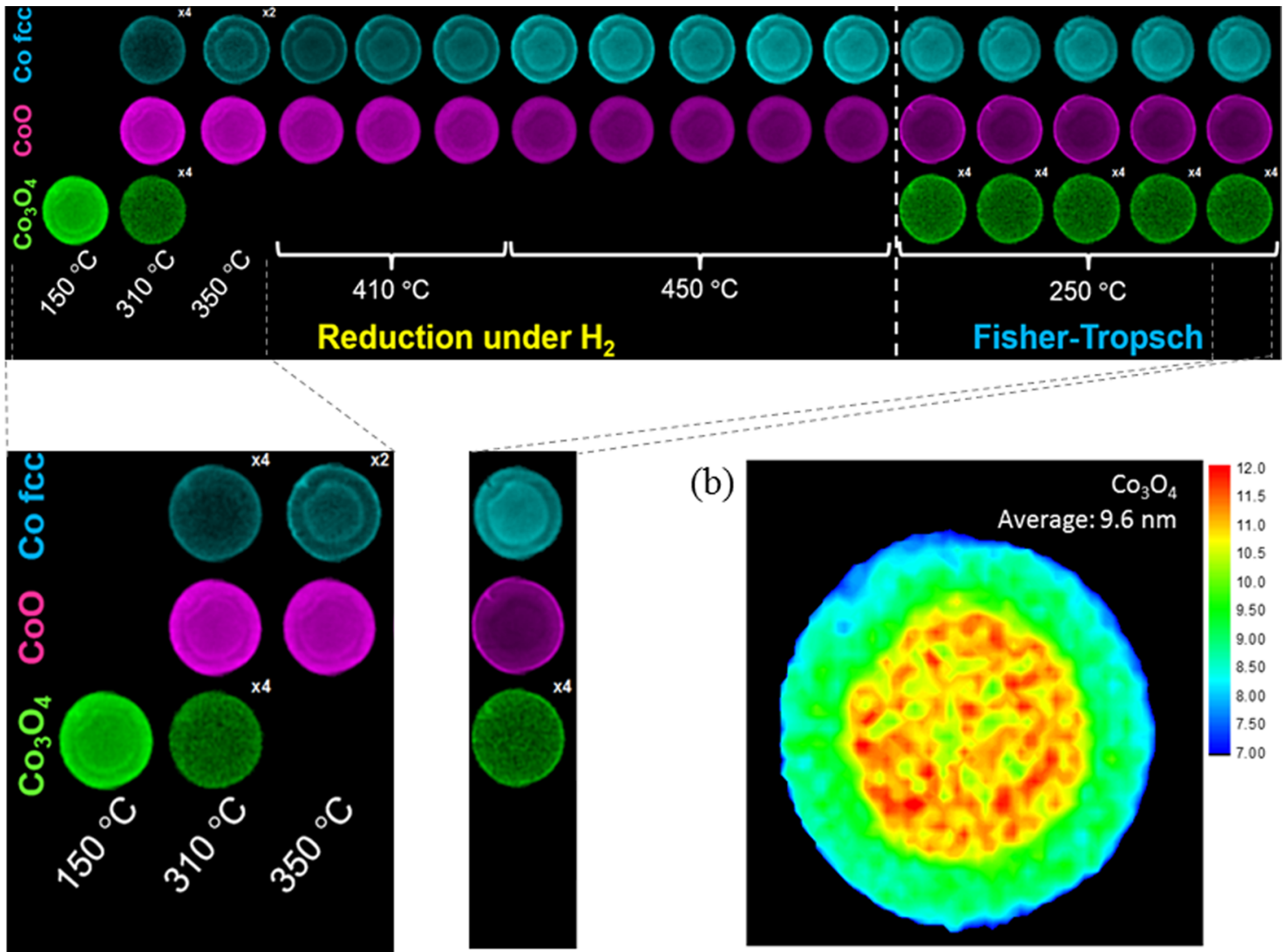

(b)

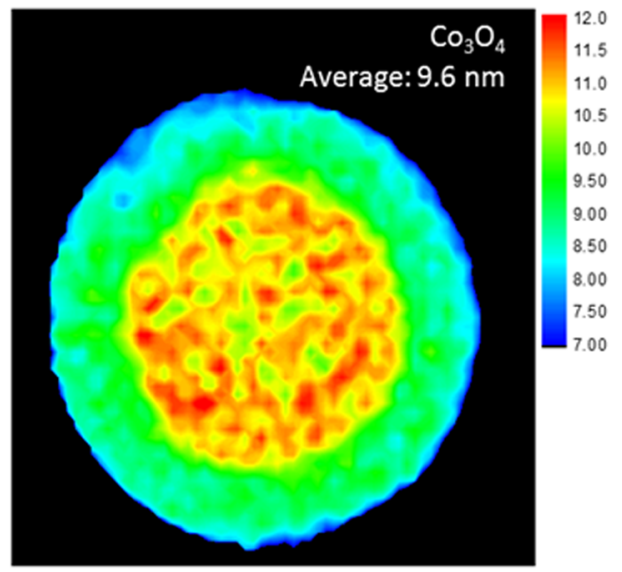

Figure 4. (a) Reconstructed 2D integrated reflection intensity maps for $\mathrm{Co}_{3} \mathrm{O}_{4}(220), \mathrm{CoO}(200)$, and fcc $\mathrm{Co}$ (111) observed under reduction and during FTS conditions as a function of temperature and time. Since the acquisition of the 2D data took $\sim 60$ min, there are 10 observation steps as the sample is reduced, although there are only 3 during the initial temperature ramping. Multipliers depicted in the right-hand corner of some of the intensity maps (particularly $\mathrm{Co}_{3} \mathrm{O}_{4}$ ) illustrate how the integrated intensity has been multiplied so to enable plotting on a common intensity axis. We note that the Bragg reflection intensity for $\mathrm{Co}_{3} \mathrm{O}_{4}$ is very weak and therefore at the limit of what can be reliably determined, so that the proposed distribution/presence of this phase is unlikely to be real in the data recorded at $310{ }^{\circ} \mathrm{C}$. However, it is present at the sample edge in the measurements made under FTS conditions. (b) $\mathrm{Co}_{3} \mathrm{O}_{4}$ (nano)particle size distribution map recorded at $150{ }^{\circ} \mathrm{C}$ during reduction in $\mathrm{H}_{2}$.

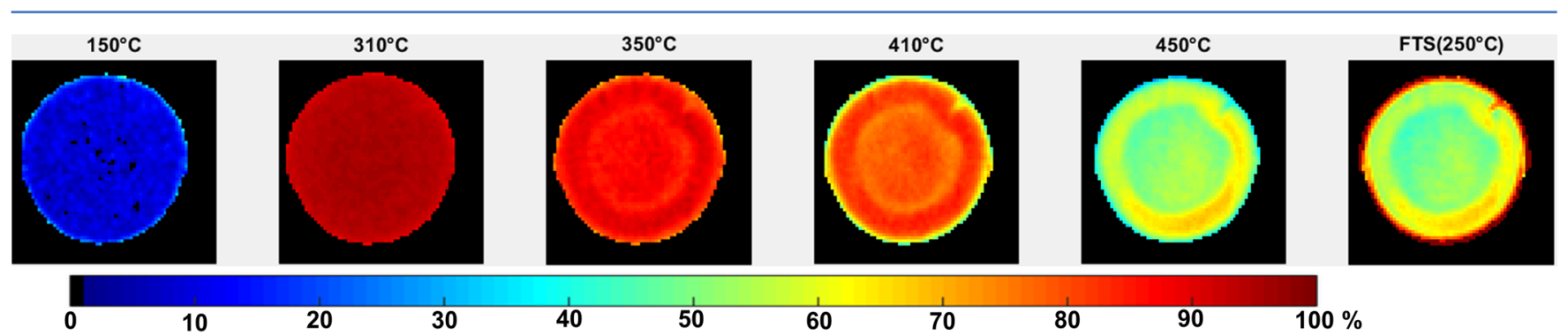

Figure 5. Reconstructed $2 \mathrm{D}$ weight percent composition maps for $\mathrm{CoO}$ observed during reduction in $\mathrm{H}_{2}$ and during FTS: balance Co $\mathrm{O}_{4}\left(150{ }^{\circ} \mathrm{C}\right)$ or else metallic fcc Co $\left(T_{\mathrm{r}}>310^{\circ} \mathrm{C}\right.$ and during FTS). A corresponding phase composition map for the fcc Co phase is also shown in Figure S3 in the Supporting Information.

Co). It is noticeable that Co reduction appears to plateau after $7 \mathrm{~h}$ at $450{ }^{\circ} \mathrm{C}$; the remaining $\mathrm{CoO}$, however, is thought to mainly reside at the interface of the Co fcc nanoparticle and the $\gamma$ - $\mathrm{Al}_{2} \mathrm{O}_{3}$ surface. ${ }^{10,35}$ On switchover to FTS reaction conditions, however, there is a significant reduction in the Co fcc 111 reflection intensity while, at the same time, a very slight initial increase in the 200 reflection for the $\mathrm{CoO}$ phase occurs. After these changes on switchover, little further change is observed.

The spatial dependence of the phase evolution presented above was determined from the CT-reconstructed $2 \mathrm{D}$ intensity distribution maps. These are shown in Figure 4a. Starting with the initial Co distribution, on the basis of the intensity of the 220 reflection pertaining to $\mathrm{Co}_{3} \mathrm{O}_{4}$ which we take as an indication of the distribution of cobalt in general, we observe the distribution to be slightly unusual, ostensibly being describable as egg white, since the Co is mainly concentrated toward the outer $0.5 \mathrm{~mm}$ of the $\gamma-\mathrm{Al}_{2} \mathrm{O}_{3}{ }^{36} \mathrm{In}$ addition and further toward the center there is a second zone of high Co concentration in the form of a ring some $150 \mu \mathrm{m}$ thick. Moving toward the particle center, the distribution appears increasingly more uniform. A map of $\mathrm{Co}_{3} \mathrm{O}_{4}$ nanocrystallite size was obtained from the full-width at half-maximum (fwhm) data of the profiled reflection using the Scherrer equation (and assuming the particles to be isotropic) and showed that larger particles were typically present in the central $2 \mathrm{~mm}$ diameter of the sample $(10-12 \mathrm{~nm})$ than at the outer $1 \mathrm{~mm}(7-9.5 \mathrm{~nm})$ 


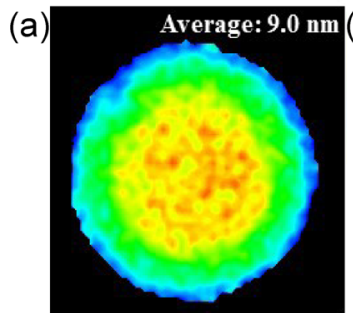

$(\mathrm{C})$

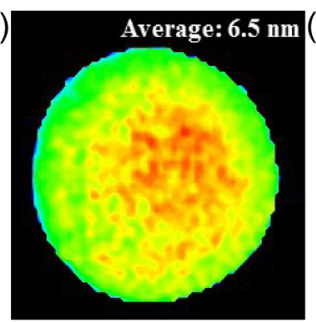

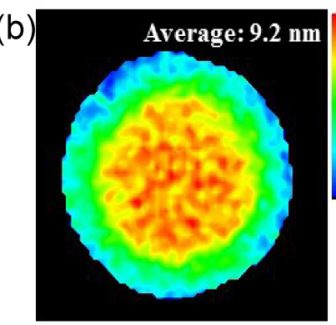

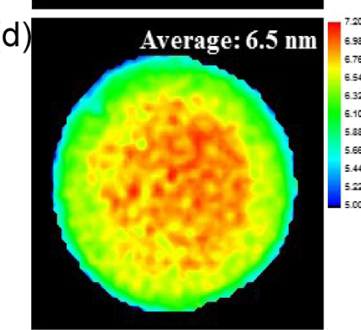

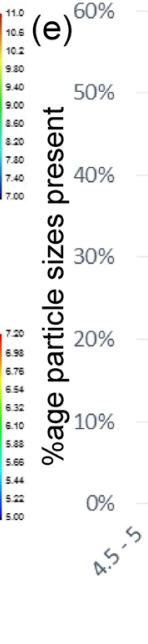

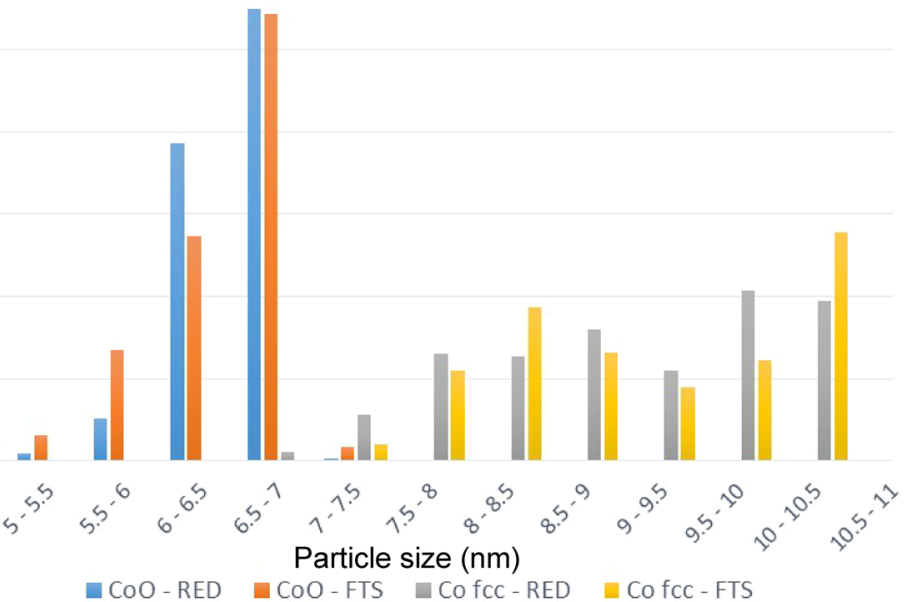

Figure 6. Reconstructed images of cobalt nanocrystallite size observed at the end of the reduction and during FTS for fcc Co (a, b) and CoO (c, d), respectively. Note that the units for the scale bars in (b) and (d) are nanometers and that the scale bars are applicable also to the reduction data shown in (a) and (c). In (e) is given a histogram plot detailing the number of times an average particle size is observed for the fcc Co or CoO phase in images $(\mathrm{a})-(\mathrm{d})$.

(see Figure $4 \mathrm{~b}$ ). We propose that such a distribution is likely to have arisen as a result of the impregnation and drying stage in the catalyst preparation process. ${ }^{37}$

The data shown in Figure 4 confirm the same global changes reported in Figure 3, but in particular that spatially, during reduction, the Co distribution is broadly retained irrespective of $\mathrm{Co}$ phase as the $\mathrm{Co}_{3} \mathrm{O}_{4} \rightarrow \mathrm{CoO} \rightarrow \mathrm{Co}$ fcc metal phase transformation occurs with time/temperature. The Co fcc metal formation follows a "shrinking core" model for its formation, but it is of particular note that the scattering intensity increases (relative to the oxide phases) particularly at the sample edge; this is suggestive of facile Co formation at the sample edge where the oxide phases first encounter flowing $\mathrm{H}_{2}$. Of particular interest is what happens during FTS, where confirmation of a total reduction in the Co fcc (111) reflection intensity plotted in Figure 3 can be seen, but that most notably there is an increase in reflection intensity for both the $\mathrm{CoO}$ and $\mathrm{Co}_{3} \mathrm{O}_{4}$ phases at the edge of the particle.

From the ratio of the integrated and scaled intensities the weight percent of $\mathrm{CoO}$ is plotted in Figure 5, although this is done on the basis that the total Co percentage is equal to $\mathrm{CoO}$ $+\mathrm{Co}$ and therefore, by ignoring the trace amounts of $\mathrm{Co}_{3} \mathrm{O}_{4}$ and by virtue of the fact only one peak is profiled, represents a semiquantitative result. At $150{ }^{\circ} \mathrm{C}$, the deep blue color indicates the complete absence of $\mathrm{Co}$ fcc and conveys that $\mathrm{Co}_{3} \mathrm{O}_{4}$ is predominantly present, although it has begun to reduce to $\mathrm{CoO}$. The prevalence of red coloration in samples undergoing reduction between 150 and $410{ }^{\circ} \mathrm{C}$ is consistent with the maximum amount of $\mathrm{CoO}$ initially being formed at $310^{\circ} \mathrm{C}$ and gradually being reduced to fcc $\mathrm{Co}$, starting from the sample periphery on reaching $350{ }^{\circ} \mathrm{C}$ and progressing inward. Interestingly on reaching $410{ }^{\circ} \mathrm{C}$ three domains can be seen in the sample which can be loosely described as comprising $\sim 40-50 \%$ metallic fcc Co (balance $\mathrm{CoO}$ ) at the sample periphery, followed by a $0.5 \mathrm{~mm}$ radial band containing only $\sim 20 \%$ metallic fcc $\mathrm{Co}$, and finally a $2 \mathrm{~mm}$ diameter egg yolk distribution tending toward the sample center comprising 20-50\% metallic Co. These "domains" remain intact as the reduction temperature reaches $450{ }^{\circ} \mathrm{C}$, although the amount of metallic Co increases overall (i.e., a per-pixel basis) by $\sim 20 \%$.
Perhaps most striking is the observation that metallic Co is present both at the periphery of the catalyst pellet and at the core but that, in both cases, it represents about $\sim 60 \%$ of the Co content. As shown previously in Figure $4 \mathrm{a}$, the switchover to FTS sees a dramatic reduction (tending toward 90\% oxidation) in metallic Co almost exclusively at the sample periphery while the remainder of the pellet remains largely unaffected.

Figure 6 contains maps of the nanocrystallite size for the tomographic slices of $\mathrm{CoO}$ and metallic cobalt $\mathrm{Co}$ fcc at the end of the reduction and during FTS conditions. There is a clear difference between the average nanocrystallite size between the two phases; the average particle size $(\sim 6.5 \mathrm{~nm})$ and range of particle sizes $(5.0-7.2 \mathrm{~nm})$ for $\mathrm{CoO}$ is in both instances much smaller than for fcc Co $(\sim 9.0$ and $7-11 \mathrm{~nm}$ ranges) in both the sample recorded in $\mathrm{H}_{2}$ and under FTS conditions. As with the concentration (determined from the corresponding reflection intensities) there is a gradient in particle size across the sample with larger particles seen for both phases in the center of the pellet and smaller particles at the periphery (similarly sized for $\mathrm{CoO} \sim 6.1$ and $7 \mathrm{~nm}$ for fcc Co) and larger particles, although more mismatched in the center ( 7 and $10 \mathrm{~nm}$ for $\mathrm{CoO}$ and fcc $\mathrm{Co}$, respectively). There is a slight, but nonetheless definitive, change in the average particle size on switchover to FTS conditions, particularly for $\mathrm{CoO}$, with slightly larger particles seen on the inside of the sample and slightly smaller particles at the periphery (Figure 6c,d). However, for metallic fcc Co larger particles are seen in both regions (Figure 6a,b): note that Figure S4 in the Supporting Information shows the summed $\mu$-XRD-CT data for the sample delineated into the outer $0.5 \mathrm{~mm}$ periphery and an inner $2 \mathrm{~mm}$ diameter core which allows us to compare the diffraction intensity changes between the two regions in the sample after reduction and under FTS conditions. The accompanying histogram plots shown in Figure 6e illustrate these changes in particle size distribution more clearly. Specifically, smaller metallic Co fcc particles $(\leq 7.5 \mathrm{~nm})$ disappear under FTS conditions (predominantly at the sample periphery) and larger particles $(\geq 9 \mathrm{~nm})$ predominantly grow in the sample center. The growth in the fcc Co nanoparticles as evidenced by diffraction is likely to be due to oxidation of the small fcc Co 


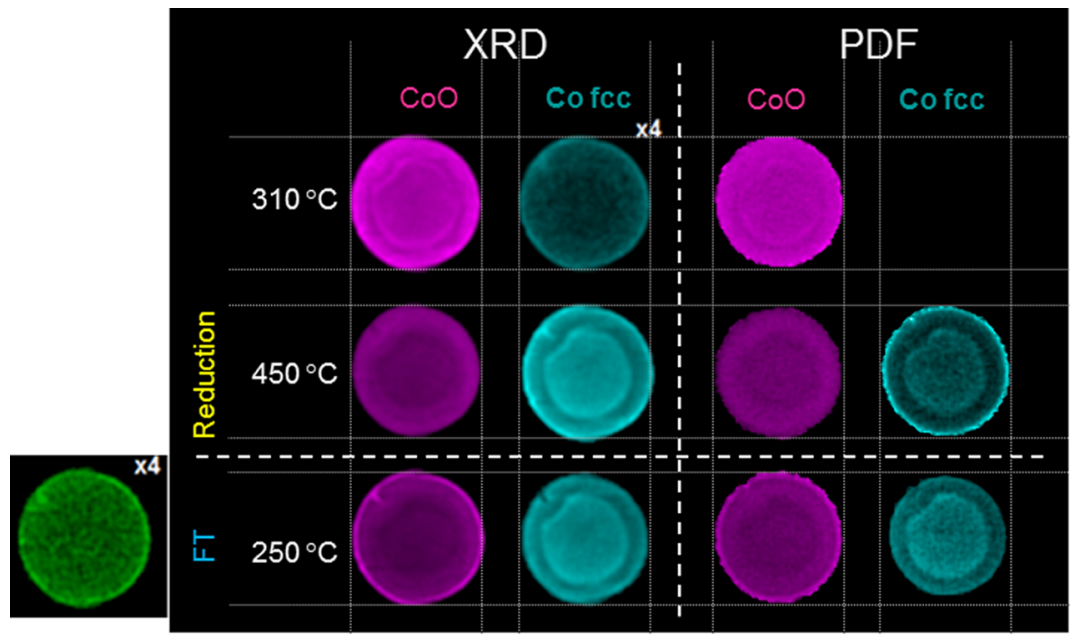

Figure 7. Reconstructed 2D integrated Fourier transform intensity maps based on the intensity of the Co-Co scattering features at $\sim 3 \AA$ (CoO) and $2.5 \AA \mathrm{fcc}$ Co (Figure S5 in the Supporting Information) observed under reduction and during FTS conditions as a function of temperature (indicated on the left-hand side) and time.

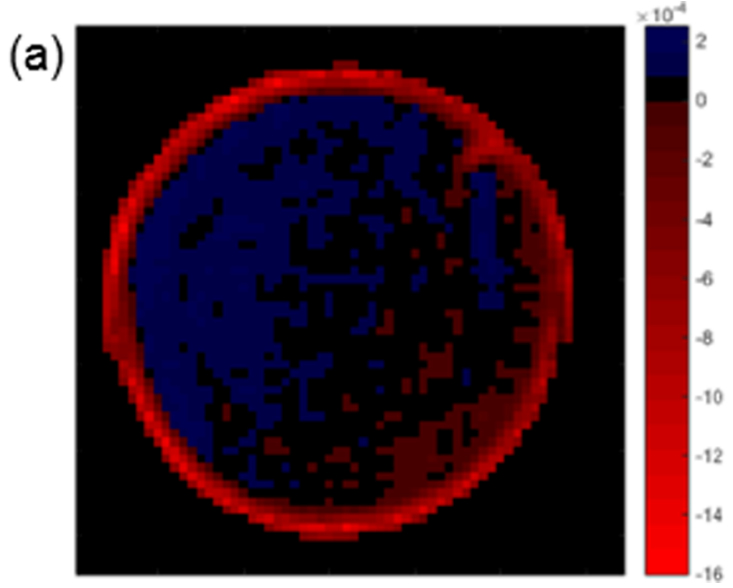

(b)

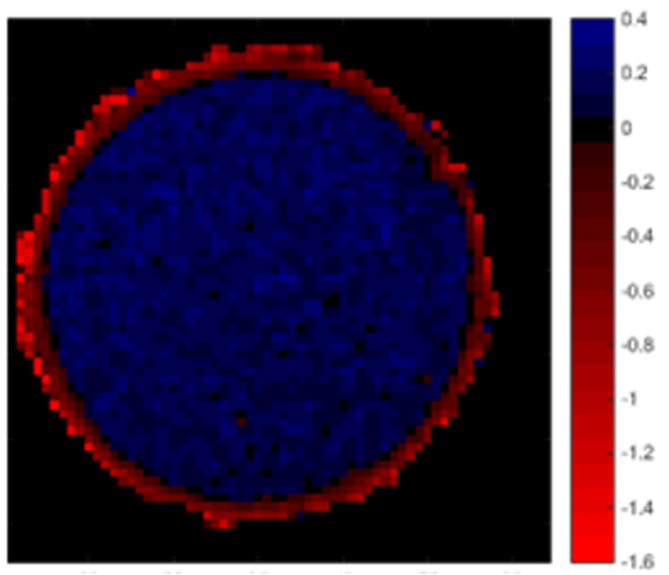

Figure 8. Subtraction of the reconstructed images of metallic cobalt phase Co fcc observed before and after switch to FTS conditions. The blue coloration indicates a gain of fcc Co, black indicates no change, and finally red indicates a loss of Co fcc from the perspective of (a) the $\mu$-XRD-CT image and (b) the $\mu$-PDF-CT image.

nanoparticles and therefore the removal of their contribution to the shape of the Bragg reflection; this oxidation is the result of water as a coproduct, which can readily oxidize small Co nanoparticles under FTS conditions. ${ }^{8,9}$ However, it is not possible to rule out that some of this growth might also be due to further $\mathrm{CoO}$ reduction and/or sintering. ${ }^{10}$

3.2. PDF-CT. Total "diffuse" scattering data provide structural information on the nature of the catalyst over many length scales and is independent of the degree of longrange ordering; thus, it is sensitive to the cobalt content present irrespective of nanoparticle size. ${ }^{38}$ In the $\mu$-CT form the first demonstration of the method revealed the presence of XRDsilent species $(\sim 1 \mathrm{~nm}$ Pd particles) distributed within the body of a supported catalyst; ${ }^{25}$ hence, a combination of $\mu$-XRD-CT and $\mu$-PDF-CT allows for a more complete evaluation of $\mathrm{Co}$ speciation.

The $\mu$-PDF-CT data collected subsequently after each $\mu$ $\mathrm{XRD}-\mathrm{CT}$ measurement on the same sample and displayed in Figure 7 have been produced on the basis of the integrated intensities from diagnostic peaks in the Fourier-transformed data using reference compounds shown in Figure S5 in the Supporting Information. As can be seen in Figure 7, the distribution of Co-containing phases during three representative stages mirrors very closely the distribution observed in the $\mu$-XRD-CT data. However, the distribution is not entirely the same with the $\mu$-PDF-CT data recorded at $310{ }^{\circ} \mathrm{C}$, suggesting the $\mathrm{CoO}$ to be better dispersed, most likely due to the presence of smaller nanocrystals not readily detected by XRD. Furthermore, at the end of the reduction $\left(450^{\circ} \mathrm{C}\right)$, the relative intensity of the $\mu$-PDF-CT signal of the $\mathrm{fcc}$ Co is greater at the sample periphery in comparison to the $\mu$-XRD-CT results, which suggests a large number of small Co fcc nanoparticles at the sample periphery. During FTS conditions $\left(250{ }^{\circ} \mathrm{C}\right)$, the reoxidation on the outer part of the catalyst seen in the $\mu$-PDF$\mathrm{CT}$ is the same as that seen in the $\mu$-XRD-CT.

Figure 8 contains a difference map detailing the change in fcc $\mathrm{Co}$ and $\mathrm{CoO}$ content present under reduction and FTS conditions, from the perspective of $\mu$-XRD-CT (a) and $\mu$-PDFCT (b), respectively. The changes seen in this figure are consistent with the overall differences already shown in Figure $4 \mathrm{~b}$ and 7 with the Co at the sample edge seen to readily oxidize under FTS conditions. However, these data also indicate a greater amount of fcc $\mathrm{Co}$ in the center of the sample. Furthermore, although there is general agreement with the 
observations made with both imaging modalities, it is clear that according to the $\mu$-XRD-CT data the extent of reoxidation, predominantly at the sample periphery, is greater than that seen by $\mu$-PDF-CT, which conversely sees a greater extent of fcc Co formation.

3.3. Catalytic Testing. The FTS performance of the $10 \mathrm{wt}$ $\% \mathrm{Co} / \mathrm{Al}_{2} \mathrm{O}_{3}$ catalyst pellets was examined at $250{ }^{\circ} \mathrm{C}$ and atmospheric pressure, using the same reaction conditions as used for the in situ $\mu$-XRD-CT/ $\mu$-PDF-CT study. As seen in Figure 9, the evolution of the mass traces of $\mathrm{CH}_{4}(\mathrm{~m} / z 15)$,

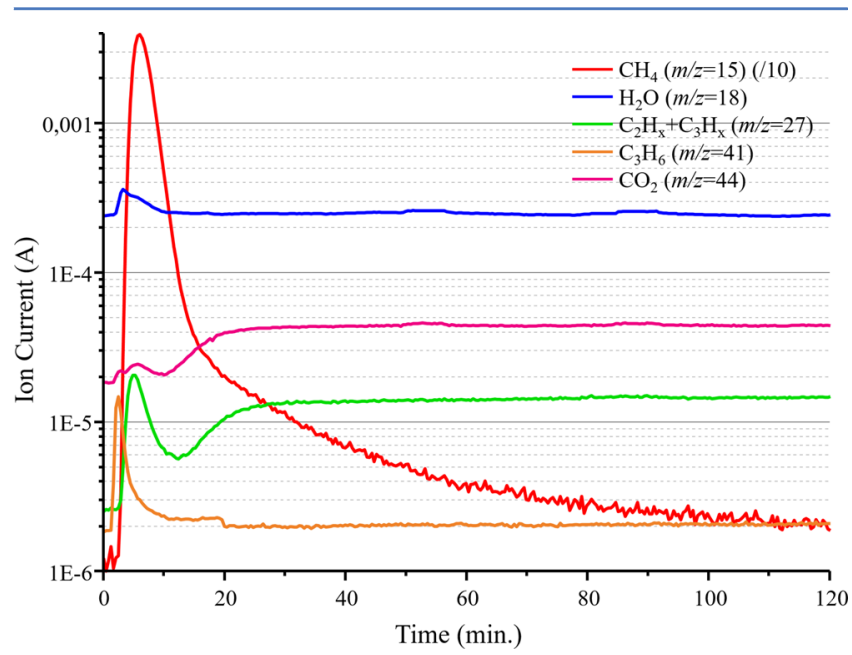

Figure 9. Mass spectrometer traces of the products formed during FTS at $250{ }^{\circ} \mathrm{C}$. The respective $m / z$ values for the product traces are given in the key at the top right-hand side.

$\mathrm{H}_{2} \mathrm{O}(\mathrm{m} / z 18), \mathrm{C}_{2} / \mathrm{C}_{3}$ hydrocarbons $(\mathrm{m} / z 27$ and 41$)$, and $\mathrm{CO}_{2}(\mathrm{~m} / z 44)$ was followed during the course of the reaction. Other masses corresponding to $\mathrm{CO}, \mathrm{H}_{2}$, and hydrocarbons were also measured (see Figure $\mathrm{S} 6$ in the Supporting Information) but are not presented here for clarity. From this figure, it can be seen that the investigated catalyst is active in FTS, confirming the validity of the approach used for the in situ study.

The results obtained show a maximum in $\mathrm{CH}_{4}(\mathrm{~m} / z 15)$ at short reaction times (ca. $6 \mathrm{~min})$, followed by a continuous decrease during the course of the reaction. The formation of $\mathrm{C}_{2}$ and $\mathrm{C}_{3}$ hydrocarbons $(\mathrm{m} / \mathrm{z} 27)$, in contrast, appears to increase and stabilize after an initial spike, indicating a gradual increment of the $\mathrm{C}_{2} / \mathrm{C}_{3}$ hydrocarbon to $\mathrm{CH}_{4}$ ratio with reaction time. Interestingly, analysis of different mass fragments corresponding to a number of olefinic and paraffinic species (i.e., $m / z 30$, $39,41,43,55,56,57$, and 58) suggests a major contribution of ethane to the $m / z 27$ peak (see Figure S6 in the Supporting Information), with only minor quantities of $\mathrm{C}_{2}$ and $\mathrm{C}_{3}$ olefinic species being formed at short reaction times $(t<20 \mathrm{~min})$. According to the Anderson-Schulz-Flory (ASF) model, the lack of $\mathrm{C}_{4+}$ products and the high $\mathrm{CH}_{4}$ selectivity (especially at short reaction times) indicate that, for the conversion level obtained here, the product distribution is shifted toward low $\alpha$ (i.e., chain growth probability) values. Furthermore, the larger amounts of paraffinic products formed (primarily ethane) suggests that carbon chain growth is terminated by hydrogenation rather than by $\beta$-hydride abstraction, although secondary hydrogenation of olefins cannot be ruled out. ${ }^{39,40}$

The evolution of $\mathrm{CO}_{2}$ was followed by the $m / z 44$ fragment and showed an upward swing in the rate of formation of $\mathrm{CO}_{2}$ after ca. $20 \mathrm{~min}$ of reaction. This $\mathrm{CO}_{2}$ response is counter to that of $\mathrm{CH}_{4}$ and suggests an onset of water-gas shift activity. Further evidence for the onset of WGS activity can be seen when considering the behavior of the $\mathrm{H}_{2} \mathrm{O}(\mathrm{m} / z 18)$ response, which reaches a maximum at short reaction times/maximum methane production $(t<15 \mathrm{~min})$, although this eventually drops due to the reaction of $\mathrm{CO}$ and the water vapor formed.

\section{DISCUSSION}

Both $\mu$-XRD-CT and $\mu$-PDF-CT demonstrate that the cobalt environment in the sample undergoes a number of changes during reduction and under FTS conditions, with these changes showing a strong spatial dependence. Importantly, this spatial dependence allows us to determine new insights into the behavior of the cobalt species and perhaps more importantly indicates spatially where the core catalytic chemistry is going on in the sample.

Let us first consider the first stage of reduction of $\mathrm{Co}_{3} \mathrm{O}_{4}$ to $\mathrm{CoO}$. This begins already at $150{ }^{\circ} \mathrm{C}$ and is essentially complete on reaching $310{ }^{\circ} \mathrm{C}$, suggesting that the majority of cobaltcontaining species behave as if they are noninteracting (with the support), agglomerated $\mathrm{Co}_{3} \mathrm{O}_{4}$ crystallites. ${ }^{41} \mathrm{We}$ observe that, although the Co distributions according to the $\mu$-XRD-CT and $\mu$-PDF-CT are similar, they are not the same. The difference between the two "observations" are most striking during reduction at $310^{\circ} \mathrm{C}$, where the $\mathrm{CoO}$ phase appears by $\mu$-PDF-CT to be more evenly distributed than that observed in $\mu$-XRD-CT. Whereas XRD essentially measures/is sensitive to crystallinity and is therefore particularly biased toward the larger crystalline domains in a material, PDF is sensitive to short-range scattering intensity irrespective of crystalline state. As such, we interpret this mismatch as evidence for the additional presence of significant amounts of nanocrystalline CoO.

The second stage of reduction of $\mathrm{CoO}$ to $\mathrm{fcc} \mathrm{Co}$ also begins at $310{ }^{\circ} \mathrm{C}$, although when the temperature reaches $450{ }^{\circ} \mathrm{C}$ reduction is only $\sim 50 \%$ complete; this average value shows a strong spatial dependence, with $\mu$-XRD-CT data showing that Co at the very edge and center of the sample are more reduced (60\%) than elsewhere in the sample ( $\sim 40 \%$ reduced). The very intense $\mu$-PDF-CT signal seen at the sample edge (especially in comparison to the center) suggests the majority of the fcc Co to be located here. The observed "shrinking-core" reduction profile seen for the $\mathrm{CoO} \rightarrow$ Co fcc metal conversion can be understood not only in terms of a greater concentration of $\mathrm{H}_{2}$ reductant at the sample periphery but also in terms of a large number of noninteracting/aggregated $\mathrm{Co}_{3} \mathrm{O}_{4}$ particles in this part of the sample. We propose that this buildup of Co in this particular part of the sample is a consequence of fast drying of the sample after impregnation, which draws the remaining mobile Co precursor using capillarity from the inner part of the sample in as the water which acts as a transport medium evaporates. $^{37,42}$

Smaller particles are easier to reduce. ${ }^{43}$ If we consider that the density of the $\mathrm{Co}_{3} \mathrm{O}_{4}$ and the fcc Co crystalline phases decreases with increasing oxygen content, we can suppose that, if only oxygen were removed from the $\mathrm{Co}_{3} \mathrm{O}_{4}$ nanoparticles, their average size should remain approximately the same as the nanoparticles transform to fcc $\mathrm{Co}$ (assuming the $\mathrm{Co}_{3} \mathrm{O}_{4}$ particles to be cuboidal and the fcc Co nanoparticles to be spherical). ${ }^{43}$ The similarity of the average particle size of $\sim 9.6$ $\mathrm{nm}$ and $2 \mathrm{D}$ distribution of particle sizes for $\mathrm{Co}_{3} \mathrm{O}_{4}$ in comparison to that seen for fcc Co $(\sim 9.0 \mathrm{~nm})$ suggests that 
the reduction process does not induce particle sintering particularly. Since the molar volume of $\mathrm{CoO}$ is approximately (90\%) that of $\mathrm{Co}_{3} \mathrm{O}_{4}$, it is safe to assume nothing dramatic changes with respect to particle size during this first stage of reduction.

The unreduced $\mathrm{CoO}$ species are likely to represent particles that are well dispersed and adhered to the $\gamma-\mathrm{Al}_{2} \mathrm{O}_{3}$ support to reduce properly under the reaction conditions employed here, as has been observed in previous studies; indeed, it has been reported that temperatures tending toward $600{ }^{\circ} \mathrm{C}$ are needed for complete reduction. ${ }^{34,41}$ Our data suggest that $\mathrm{CoO}$ particles in close contact with $\gamma-\mathrm{Al}_{2} \mathrm{O}_{3}$ do not reduce if they are $\leq 6.5 \mathrm{~nm}$ in size.

Under FTS conditions the fcc Co is seen to oxidize at the sample periphery to yield mainly $\mathrm{CoO}$ but also a small amount of $\mathrm{Co}_{3} \mathrm{O}_{4}$. This can be understood as an effect of the coproduction of water (eqs 1 and 2) with catalytic activity, particularly affecting the sample periphery, where it has been argued that, due to the diffusional limitations of CO, the FTS activity is likely to be largely confined. ${ }^{44}$ Indeed, a good correlation is seen between the water evolved during the initial stages of the reaction $(t<15 \mathrm{~min}$; Figure 9) and the oxidation of the fcc Co particles. Not all of this Co is oxidized, however, with a significant portion of Co remaining in the metallic state needed to perform the FTS reaction; there is also very little difference in particle size (by $\mu$-XRD-CT) of both fcc Co or $\mathrm{CoO}$ before and after FTS in this region of the sample. This observation regarding particle size retention taken in conjunction with the observation of a bright fcc Co signal at the sample periphery seen with $\mu$-PDF-CT after reduction can be interpreted in terms of an oxidation of a significant number of small $(<7 \mathrm{~nm})$ aggregated fcc Co particles. Within this context, it is interesting to note the shift in product distribution from methane toward ethane with increasing reaction times, which indicates a decrease in the methanation ability of the catalyst at the expense of chain growth. Importantly, this shift in selectivity appears to be related to the oxidation of the small fcc Co particles in the sample periphery, which initially possess enhanced selectivity to methane, as both observations occur simultaneously (while the rest of the pellet is seen to remain unaffected). This indicates a positive effect of (presumably) low water concentrations (i.e., produced indigenously) on the catalytic performance, as well as a certain contribution of the small fcc Co particles to the presence of larger amounts of dissociated hydrogen, necessary to produce methane. ${ }^{8,9,30,45}$

Regarding the WGS reaction, it has been previously indicated that oxidized Co sites may be responsible for an enhanced WGS activity under FTS conditions, also promoting methanation. ${ }^{15,17,46}$ Although it cannot be discarded that (the initially present) unreduced $\mathrm{CoO}$ particles partially contribute to the WGS reaction, from the data obtained it can be clearly seen that enhanced WGS activity is detected right after the small fcc Co particles become oxidized, thereby indicating a certain promotion of these species. Methane formation, in contrast, monotonically decreases over the course of the reaction, evidencing that oxidized Co particles (either present after reduction or resulting from reoxidation) are not responsible for methanation.

Finally, the oxidation of smaller particles may appear to explain the slightly larger average particle size seen for the metallic fcc Co phase during FTS (indeed, some of the smaller particles in the histogram plot in Figure 6e disappear), which in the past has been attributed to simple sintering behavior. ${ }^{10}$
However, we note further reduction/sintering of the Co nanoparticles could still occur in the sample core at relatively long reaction times $(t>2 \mathrm{~h})$; while $\mathrm{CO}$ may be diffusion limited, $\mathrm{H}_{2}$ is less so and is still able to reduce or even sinter (possibly promoted by the water byproduct) the Co nanoparticles.

\section{SUMMARY AND CONCLUSION}

Using $\mu$-XRD-CT and $\mu$-PDF-CT to obtain information on the spatial distribution of the various Co-containing phases over a $\mathrm{Co} / \gamma-\mathrm{Al}_{2} \mathrm{O}_{3}$ catalyst pellet during reduction and under FTS conditions allowed us to examine the rich chemistry of these $\mathrm{Co} / \gamma-\mathrm{Al}_{2} \mathrm{O}_{3}$ catalysts as a function of the spatial distribution of the sample. Some imperfection in the catalyst preparation processes results in a range of species being produced, which can be broadly classified as follows. (a) There are two types of $\mathrm{Co}_{3} \mathrm{O}_{4}$ particles present at the beginning-those which are well dispersed and therefore interact strongly with the $\gamma-\mathrm{Al}_{2} \mathrm{O}_{3}$ support, and those which are poorly dispersed/aggregated that do not interact well with the support. The former, when they are $\lesssim 6.5 \mathrm{~nm}$, cannot be fully reduced and remain as $\mathrm{CoO}$ during reduction treatment, whereas the latter reduce more easily. (b) $\mu$-XRD-CT and $\mu$-PDF-CT suggest that the majority of the aggregated particles can be found at the very edge of the sample and, to a somewhat lesser extent, in the central $2.5 \mathrm{~mm}$ diameter of the pellet. The smaller nanoparticles at the sample edge appear to reduce more quickly than the larger particles on the inside of the sample (we note that $\left[\mathrm{H}_{2}\right]$ is likely to be greater at the periphery so that it cannot be ascribed to simply a particle size effect). However, these particles also oxidize more readily on switchover to FTS (due to water produced in the reaction), since we observe an average metallic fcc Co particle size increase at the periphery.

The results obtained in this study illustrate the challenge in creating a structured FTS-active $\mathrm{Co} / \gamma-\mathrm{Al}_{2} \mathrm{O}_{3}$ pellet. They suggest that the use of a high-surface-area $\gamma-\mathrm{Al}_{2} \mathrm{O}_{3}$ is not always beneficial, as it will increase the number of Co nanoparticle- $\gamma$ $\mathrm{Al}_{2} \mathrm{O}_{3}$ interactions which will require higher reduction temperatures (and/or time) or else the use of promoters in order to reduce to an active fcc Co form. ${ }^{3,16}$ The risk of using these higher temperatures (tending toward $600{ }^{\circ} \mathrm{C}$ ) is the increased probability of a solid-state reaction to form the inactive $\mathrm{CoAl}_{2} \mathrm{O}_{4}$. phase. $^{35,47}$ Aggregated particles that are not in direct contact with the support then could be considered the preferred species, although the challenge here is to narrow the particle size distribution sufficiently so as to eliminate particles that are either too large (low turnover) or, as this study illustrates, too small $(\leq 7.5 \mathrm{~nm})$ to remain in the active metallic form (and to provide the desired product selectivity). This reoxidation behavior for such $\mathrm{fcc}$ Co particles on $\mathrm{Co} / \gamma$ $\mathrm{Al}_{2} \mathrm{O}_{3}$ also illustrates the difficulty in translating a particular Co particle size for FTS activity across different support types. ${ }^{29,45}$ Indeed, our results illustrate that not only are the smaller species active in methanation but also they eventually become active in WGS and hence are clearly very undesirable for the production of $\mathrm{C}_{2}{ }^{+}$species. Clearly then at the $\mu$ scale, the distribution of these stable and active species should be biased toward the sample periphery for optimal activity, especially toward $\mathrm{C}_{2}{ }^{+}$species. ${ }^{44}$

As is typical of all structured heterogeneous catalysts, a mixture of Co-containing phases was detected in the sample and these results act as a powerful illustration of how the techniques of $\mu$-XRD-CT and $\mu$-PDF-CT can put changes in 
phase evolution into spatial context which could not be realized when the bulk is measured via a single-point measurement. With the advancements in synchrotron brightness, detector performance, and sample environment these types of measurements are becoming increasingly routine and will eventually prompt us to consider that all industrial catalysts should be chemically imaged in situ in order to put the evolving solidstate chemistry into the context of catalytic performance.

\section{ASSOCIATED CONTENT}

\section{S Supporting Information}

The Supporting Information is available free of charge on the ACS Publications website at DOI: 10.1021/acscatal.6b03145.

Additional information regarding the experimental methodology and data analysis (PDF)

\section{AUTHOR INFORMATION}

\section{Corresponding Author}

*E-mail for A.M.B.: andrew.beale@ucl.ac.uk.

\section{ORCID}

Andrew M. Beale: 0000-0002-0923-1433

Notes

The authors declare no competing financial interest.

\section{ACKNOWLEDGMENTS}

The authors gratefully acknowledge BP and EPSRC (EP/ K007467/1) for funding and ESRF for beamtime.

\section{REFERENCES}

(1) Nguyen, V. N.; Blum, L. Chem. Ing. Tech. 2015, 87 (4), 354-375.

(2) Ail, S. S.; Dasappa, S. Renewable Sustainable Energy Rev. 2016, 58, 267-286.

(3) Khodakov, A. Y.; Chu, W.; Fongarland, P. Chem. Rev. 2007, 107 (5), 1692-1744.

(4) Zhong, L.; Yu, F.; An, Y.; Zhao, Y.; Sun, Y.; Li, Z.; Lin, T.; Lin, Y.; Qi, X.; Dai, Y.; Gu, L.; Hu, J.; Jin, S.; Shen, Q.; Wang, H. Nature 2016, 538 (7623), 84-87.

(5) Xiang, Y.; Kruse, N. Nat. Commun. 2016, 7, 13058.

(6) Rytter, E.; Tsakoumis, N. E.; Holmen, A. Catal. Today 2016, 261, $3-16$.

(7) Tsakoumis, N. E.; Voronov, A.; Ronning, M.; van Beek, W.; Borg, O.; Rytter, E.; Holmen, A. J. Catal. 2012, 291, 138-148.

(8) Fischer, N.; Clapham, B.; Feltes, T.; Claeys, M. ACS Catal. 2015, $5(1), 113-121$.

(9) Fischer, N.; Clapham, B.; Feltes, T.; van Steen, E.; Claeys, M. Angew. Chem., Int. Ed. 2014, 53 (5), 1342-1345.

(10) Karaca, H.; Hong, J.; Fongarland, P.; Roussel, P.; GribovalConstant, A.; Lacroix, M.; Hortmann, K.; Safonova, O. V.; Khodakov, A. Y. Chem. Commun. 2010, 46 (5), 788-790.

(11) Cats, K. H.; Gonzalez-Jimenez, I. D.; Liu, Y.; Nelson, J.; van Campen, D.; Meirer, F.; van der Eerden, A. M. J.; de Groot, F. M. F.; Andrews, J. C.; Weckhuysen, B. M. Chem. Commun. 2013, 49 (41), $4622-4624$.

(12) Herbert, J. J.; Senecal, P.; Martin, D. J.; Bras, W.; Beaumont, S. K.; Beale, A. M. Catal. Sci. Technol. 2016, 6 (15), 5773-5791.

(13) Tsakoumis, N. E.; Ronning, M.; Borg, O.; Rytter, E.; Holmen, A. Catal. Today 2010, 154 (3-4), 162-182.

(14) Lancelot, C.; Ordomsky, V. V.; Stephan, O.; Sadeqzadeh, M.; Karaca, H.; Lacroix, M.; Curulla-Ferre, D.; Luck, F.; Fongarland, P.; Griboval-Constant, A.; Khodakov, A. Y. ACS Catal. 2014, 4 (12), 4510-4515.

(15) Dalai, A. K.; Das, T. K.; Chaudhari, K. V.; Jacobs, G.; Davis, B. $\mathrm{H}$. Fischer-Tropsch synthesis: Water effects on Co supported on narrow and wide-pore silica. Appl. Catal., A 2005, 289 (2), 135-142.
(16) Das, T. K.; Jacobs, G.; Davis, B. H. Catal. Lett. 2005, 101 (3-4), 187-190.

(17) Jacobs, G.; Patterson, P. M.; Das, T. K.; Luo, M. S.; Davis, B. H. Appl. Catal., A 2004, 270 (1-2), 65-76.

(18) Synthesis of Solid Catalysts; de Jong, K. P., Ed.; Wiley-VCH: Weinheim, Germany, 2009.

(19) Beale, A. M.; Jacques, S. D. M.; Weckhuysen, B. M. Chem. Soc. Rev. 2010, 39 (12), 4656-4672.

(20) Grunwaldt, J. D.; Wagner, J. B.; Dunin-Borkowski, R. E. Chem CatChem 2013, 5 (1), 62-80.

(21) Beale, A. M.; Jacques, S. D. M.; Gibson, E. K.; Di Michiel, M. Coord. Chem. Rev. 2014, 277-278, 208-223.

(22) O’Brien, M. G.; Jacques, S. D. M.; Di Michiel, M.; Barnes, P.; Weckhuysen, B. M.; Beale, A. M. Chem. Sci. 2012, 3 (2), 509-523.

(23) Price, S. W. T.; Geraki, K.; Ignatyev, K.; Witte, P. T.; Beale, A. M.; Mosselmans, J. F. W. Angew. Chem., Int. Ed. 2015, 54 (34), 98869889.

(24) Cats, K. H.; Andrews, J. C.; Stephan, O.; March, K.; Karunakaran, C.; Meirer, F.; de Groot, F. M. F.; Weckhuysen, B. M. Catal. Sci. Technol. 2016, 6 (12), 4438-4449.

(25) Jacques, S. D. M.; Di Michiel, M.; Kimber, S. A. J.; Yang, X.; Cernik, R. J.; Beale, A. M.; Billinge, S. J. L. Nat. Commun. 2013, 4, 2536.

(26) http://www.datasqueezesoftware.com/index.html (date of access 26/01/2016).

(27) Farrow, C. L.; Juhas, P.; Liu, J. W.; Bryndin, D.; Bozin, E. S.; Bloch, J.; Proffen, T.; Billinge, S. J. L. J. Phys.: Condens. Matter 2007, 19 (33), 335219.

(28) Juhas, P.; Davis, T.; Farrow, C. L.; Billinge, S. J. L. J. Appl. Crystallogr. 2013, 46, 560-566.

(29) den Breejen, J. P.; Sietsma, J. R. A.; Friedrich, H.; Bitter, J. H.; de Jong, K. P. J. Catal. 2010, 270 (1), 146-152.

(30) Bezemer, G. L.; Bitter, J. H.; Kuipers, H.; Oosterbeek, H.; Holewijn, J. E.; Xu, X. D.; Kapteijn, F.; van Dillen, A. J.; de Jong, K. P. J. Am. Chem. Soc. 2006, 128 (12), 3956-3964.

(31) Wen, C.; Dunbar, D.; Zhang, X.; Lauterbach, J.; HattrickSimpers, J. Chem. Commun. 2014, 50 (35), 4575-4578.

(32) Toby, B. H.; Von Dreele, R. B. J. Appl. Crystallogr. 2013, 46, $544-549$.

(33) Fischer, N.; van Steen, E.; Claeys, M. Catal. Today 2011, 171 (1), 174-179.

(34) Hoydalsvik, K.; Floystad, J. B.; Voronov, A.; Voss, G. J. B.; Esmaeili, M.; Kehres, J.; Granlund, H.; Vainio, U.; Andreasen, J. W.; Ronning, M.; Breiby, D. W. J. Phys. Chem. C 2014, 118 (5), 23992407.

(35) du Plessis, H. E.; Forbes, R. P.; Barnard, W.; Erasmus, W. J.; Steuwer, A. Phys. Chem. Chem. Phys. 2013, 15 (28), 11640-11645.

(36) Neimark, A. V.; Kheifez, L. I.; Fenelonov, V. B. Ind. Eng. Chem. Prod. Res. Dev. 1981, 20 (3), 439-450.

(37) Espinosa-Alonso, L.; Beale, A. M.; Weckhuysen, B. M. Acc. Chem. Res. 2010, 43 (9), 1279-1288.

(38) Egami, T.; Billinge, S. J. L. Underneath the Bragg Peaks: Structural Analysis of Complex Materials, 2nd ed.; Elsevier: Amsterdam, 2012; Vol. 16, pp 1-481.

(39) Anderson, R. B.; Friedel, R. A.; Storch, H. H. J. Chem. Phys. 1951, 19 (3), 313-319.

(40) Roferdepoorter, C. K. Chem. Rev. 1981, 81 (5), 447-474.

(41) Jacobs, G.; Das, T. K.; Zhang, Y.; Li, J.; Racoillet, G.; Davis, B. H. Appl. Catal., A 2002, 233 (1-2), 263-281.

(42) Gibson, E. K.; Zandbergen, M. W.; Jacques, S. D. M.; Biao, C.; Cernik, R. J.; O’Brien, M. G.; Di Michiel, M.; Weckhuysen, B. M.; Beale, A. M. ACS Catal. 2013, 3 (3), 339-347.

(43) Sadasivan, S.; Bellabarba, R. M.; Tooze, R. P. Nanoscale 2013, 5 (22), 11139-11146.

(44) Iglesia, E.; Soled, S. L.; Baumgartner, J. E.; Reyes, S. D. J. Catal. 1995, 153 (1), 108-122.

(45) den Breejen, J. P.; Radstake, P. B.; Bezemer, G. L.; Bitter, J. H.; Froseth, V.; Holmen, A.; de Jong, K. P. J. Am. Chem. Soc. 2009, 131 (20), 7197-7203. 
(46) Ma, W. P.; Jacobs, G.; Ji, Y. Y.; Bhatelia, T.; Bukur, D. B.; Khalid, S.; Davis, B. H. Top. Catal. 2011, 54 (13-15), 757-767.

(47) Beale, A. M.; Sankar, G. Chem. Mater. 2006, 18 (2), 263-272. 